\title{
Multiple Subcellular Localizations of Dehydrin-like Proteins in the Embryonic Axes of Common Beech (Fagus sylvatica L.) Seeds During Maturation and Dry Storage
}

\author{
Ewa Marzena Kalemba • Agnieszka Bagniewska-Zadworna • \\ Ewelina Ratajczak
}

Received: 25 March 2014/ Accepted: 29 July 2014/Published online: 23 August 2014

(C) The Author(s) 2014. This article is published with open access at Springerlink.com

\begin{abstract}
The accumulation and localization of dehydrinlike proteins were analyzed in the embryonic axes of beech (Fagus sylvatica L.) seeds during maturation between the 12th and 19th week after flowering and in the dry state after 2 years of storage. Three dehydrin-like proteins were reported using an antibody specific to the K-segment, and their subcellular localization was investigated using an immunocytochemistry approach. All dehydrin-like proteins were phosphorylated, and two, with molecular masses of 26 and $44 \mathrm{kDa}$, accumulated in mature seeds. During seed maturation, dehydrin-like proteins were frequently detected inside the round or segmented nuclei, along the cell plasma membrane and associated with small vesicles. Moreover, they were found to be attached to the mitochondrial and amyloplast envelopes. These proteins were also located in the cytosol and were associated with membrane structures throughout the cytoplasm. Conversely, in the embryonic axes of stored seeds, fewer specific locations were found; dehydrin-like proteins were associated mostly with amyloplasts, and were detected to a lesser extent in the nuclei, vacuoles, and other cytoplasmic structures. Bioinformatic tools were used to predict the putative beech dehydrin sites that interact with DNA, proteins, and lipid membranes to
\end{abstract}

Electronic supplementary material The online version of this article (doi:10.1007/s00344-014-9451-z) contains supplementary material, which is available to authorized users.

E. M. Kalemba $(\bowtie) \cdot$ E. Ratajczak

Laboratory of Seed Biochemistry, Institute of Dendrology,

Polish Academy of Sciences, Kórnik, Poland

e-mail: kalemba@man.poznan.pl; ewa.kalemba@gmail.com

A. Bagniewska-Zadworna

Department of General Botany, Faculty of Biology, Institute of Experimental Biology, Adam Mickiewicz University,

Umultowska 89, Poznan, Poland highlight the reported subcellular locations. Here, we present and discuss the possible roles of dehydrin-like proteins in seeds with respect to their subcellular localizations.

Keywords Beech · Dehydrin · Seed development $\cdot$ Seed storage $\cdot$ Subcellular localization

\section{Introduction}

Common beech (Fagus sylvatica L.) is native throughout almost all of Europe and produces seeds in large intervals, which were classified at first into the intermediate category (Bonner 1990; Gosling 1991) and then into the orthodox category (Poulsen 1993; Poulsen and Kundsen 1999). During development, beech seeds become desiccation tolerant beginning at the 16th week after flowering (WAF) (Kalemba and others 2009) like all other orthodox type seeds (Roberts 1973). Beech seeds were finally classified into the intermediate category (León-Lobos and Ellis 2002) due to their reduced longevity during storage (León-Lobos and Ellis 2002; Pukacka and Ratajczak 2007; Kalemba and Pukacka 2014); the seeds cannot survive dehydration below those in equilibrium with approximately 40-50\% relative humidity (Ellis and others 1990).

Late embryogenesis abundant (LEA) proteins, including dehydrins, are hydrophilic molecules accumulated during development and water stress (reviewed in Rorat 2006; Battaglia and others 2008; Hara 2010; Battaglia and Covarrubias 2013). Dehydrins, group 2 of the LEA proteins, are characterized by highly conserved sequences, including a lysine-rich K-segment, a polyserine S-segment, a Y-segment, and a $\Phi$-segment (Close 1996). The K-segment uniquely contains the consensus amino acid sequence 
EKKGIMDKIKELPG, which is present in all types of dehydrins (Close 1997). Despite the conserved dehydrin sequences, they appear to be intrinsically disordered proteins that may exert chaperone activity through an entropy transfer mechanism (Tompa and Csermely 2004). Structural disorder confers the ability to carry out more than one function (Kovacs and others 2008). Dehydrins are synthesized during seed development as an element of the embryogenesis program, and their accumulation is related to the acquisition of desiccation tolerance (Close 1996; Kalemba and others 2009). The structural and functional characteristics of LEA proteins are being investigated to understand their role during the adaptive response to water deficit in plants (Rorat 2006; Battaglia and others 2008; Hara 2010; Battaglia and Covarrubias 2013). LEA proteins can prevent protein aggregation (Goyal and others 2005) and protect cellular macromolecules and membranes under cellular dehydration (Rorat 2006; Battaglia and others 2008; Hara 2010; Battaglia and Covarrubias 2013). The proteins may exhibit radical scavenging activity (Hara and others 2004) and act as membrane and protein stabilizers during water stress either by direct interaction or by acting as molecular shields (Tunnacliffe and Wise 2007). Dehydrins and dehydrin-related proteins were detected in many plant seeds, including the orthodox woody plant seeds (Greggains and others 2000; Kalemba and Pukacka 2012), intermediate seeds (Kalemba and Pukacka 2008), and many recalcitrant woody plant seeds (Finch-Savage and others 1994; Sunderlikova and others 2009; Panza and others 2007; Vornam and others 2011; Farias-Soares and others 2013). Dehydrins present with different tissue localization during optimal growth conditions. Immunohistochemical localization of dehydrins demonstrated tissue and cell-type specificity in unstressed Arabidopsis thaliana plants, which suggested functional specialization for members of the dehydrin family (Nylander and others 2001). RAB1 localization in provascular tissue of the cotyledons and the radicle was reported in Arabidopsis seeds (Nylander and others 2001) and in maturing pea seeds (Garnczarska and others 2008). Dehydrins were also detected in wheat crown tissues (Houde and others 1995), and bark tissues of current-year-shoots of peach (Wisniewski and others 1999). Interestingly, subcellular investigations revealed that dehydrins were reported in chloroplasts (Mueller and others 2003), mitochondria (Borovskii and others 2005), endoplasmic reticulum (Neven and others 1993), amyloplasts (Rinne and others 1999), and in the plasma membrane vicinity (Danyluk and others 1998) of seedlings or mature plant organs. In seeds, dehydrins have been immunolocalized at the subcellular level to the cytoplasm and nucleus (Asghar and others 1994; Close 1996; Egerton-Warburton and others 1997; Panza and others 2007; Carjuzaa and others 2008; Lin and others 2012). Dehydrins have also been found associated with cytoskeletal elements, the plasma membrane, the matrix of protein bodies, mitochondria, rough endoplasmic reticulum cisternae and proplastid membranes in quinoa (Carjuzaa and others 2008), and microbodies of Araucaria angustifolia (Bert.) embryos (Farias-Soares and others 2013).

To address the question of the potential roles of dehydrins and dehydrin-like proteins in beech seeds, we analyzed their subcellular localization during the seed maturation stage and in dry, stored seeds. The functions of dehydrin proteins are largely unknown. Therefore, we decided to investigate their potential role in cell protection during natural dehydration during seed development and seed storage.

\section{Materials and Methods}

\section{Material Collection}

Common beech ( $F$. sylvatica L.) seeds were collected in the cropping year 2009 in Kórnik Arboretum (Western Poland, $52^{\circ} 24^{\prime} 37^{\prime \prime} \mathrm{N} 17^{\circ} 09^{\prime} 515^{\prime \prime} \mathrm{E}$ ) from a single tree every 7 or 10 days beginning from the 12th WAF up to the 19th WAF. Nineteenth WAF seeds were considered as fully mature because it was the time when the shedding began. Seeds intended for protein isolation were prepared for storage at $-80{ }^{\circ} \mathrm{C}$. The seed coats were removed, and embryonic axes were isolated from cotyledons because all analyses were performed using embryonic axes only. Preparation of the maturating seeds intended for immunocytochemistry was initiated immediately after harvesting. The water content (dry weight basis) was determined at each seed collection. One seedlot of beech seeds from the same tree was stored at $-10{ }^{\circ} \mathrm{C}$ in closed plastic boxes at 8-9 \% water content for 2 years, and these seeds were then used for the immunocytochemistry analyses.

\section{Protein Extraction and Electrophoresis}

Embryonic axes were ground to a powder in liquid nitrogen. To obtain soluble proteins, the dried powder was homogenized at $4{ }^{\circ} \mathrm{C}$ in a $1: 2(\mathrm{w}: \mathrm{v})$ extraction buffer containing $20 \mathrm{mM}$ Tris- $\mathrm{HCl}, \mathrm{pH}$ 7.5, $5 \%$ glycerol, $10 \mathrm{mM}$ DTT, and $1 \%$ protease inhibitor cocktail (Sigma-Aldrich, Poland) and $1.5 \%$ polyvinylpolypyrrolidone (Sigma-Aldrich, Poland); the samples were further centrifuged $\left(20,000 \times g\right.$ at $4{ }^{\circ} \mathrm{C}$ for $20 \mathrm{~min}$ ). Protein concentration was measured according to the Bradford (1976) method using bovine albumin as a standard. Proteins were resolved with $12 \%$ SDS-PAGE (Laemmli 1970) using the Mini-PROTEAN ${ }^{\circledR}$ Tetra Cell (Bio-Rad) system and were stained with silver nitrate 
according to the method of Sinha and others (2001). To visualize phosphoproteins, gels were stained with Pro- $\mathrm{Q}^{\circledR}$ Diamond (Invitrogen) according to the standard manufacturer's protocol. The images were documented on a fluorescence imager (Ettan DIGE Imager, GE Healthcare) with excitation/emission settings at 555/580 nm.

\section{Alkaline Phosphatase Treatment}

Alkaline phosphatase treatment was performed on the soluble protein fractions extracted from the embryonic axes of beech seeds stored for 2 years. For enzymatic dephosphorylation, $100 \mathrm{mg}$ of protein extract was treated with 4 units of calf intestine alkaline phosphatase (Sigma-Aldrich, Poland). The reaction was performed in CIP buffer with the enzyme at $37^{\circ} \mathrm{C}$ for $16 \mathrm{~h}$.

\section{Western Blot}

The protein extract $(12.5 \mu \mathrm{g})$ was loaded onto a gel. The amount was calculated based on the calibration curve data in which the relationship between Western blot band intensities and the amount of the loaded protein was linear (correlation coefficient, $r=0.98$ ). The fractioned proteins were transferred onto a polyvinylidene fluoride membrane (Immobilon ${ }^{\mathrm{TM}}-\mathrm{P}$, Millipore) at $350 \mathrm{~mA}$ for $1 \mathrm{~h}$ and were then blocked and incubated with a rabbit primary antibody (dilution 1:1,000) raised against the dehydrin consensus K-segment (Close and others 1993). The secondary antibody was conjugated with alkaline phosphatase (SigmaAldrich, Poland) and was used in 1:10,000 dilutions. Protein bands were visualized on the membrane by reaction with an alkaline phosphate substrate (5-bromo-4-chloro-3indolyl phosphate/nitro blue tetrazolium) (Sigma-Aldrich). Control immunoassays were also performed with the dehydrin K-segment specific antibody blocked with the synthetic peptide TGEKKGIMDKIKEKLPGQH (Close and others 1993).

\section{Densitometry Analysis}

Western blot images, in triplicate, were analyzed using the UviBand (UviTec) program with a Fire Reader Gel Documentation System. Densitometry image analysis was based on the digitalization of the image in pixels with intensity coded on a scale of 256 gray levels. The density of a spot was calculated from its volume $(V)$, which is a sum of all 3D intensities $(I)$. The data were presented in relative units obtained from $V=\Sigma n_{\mathrm{i}} I$ and from the number of pixels inside the area of the spot.
Immunocytochemistry

To determine localization of the dehydrin-like proteins, the samples were treated according to the procedure described by Bagniewska-Zadworna (2008) with small modifications. The material was fixed in $0.5 \%(\mathrm{v} / \mathrm{v})$ glutaraldehyde and $4 \%$ formaldehyde in $0.1 \mathrm{M}$ sodium cacodylate buffer $(\mathrm{pH}$ 7.2) for $2 \mathrm{~h}$ at $4{ }^{\circ} \mathrm{C}$. After dehydrating in a graded ethanol series, material was embedded in LR White resin (Sigma) and sectioned using an ultramicrotome Reichert Ultracut $S$ (Leica). Moreover, before the experiment, osmium tetroxide post-fixation and embedding in the Spurr's resin were also used to verify the ultrastructure of each cell compartment and tissues of the material analyzed, according to the procedure described by Bagniewska-Zadworna and others (2010). The analyzed cells came from the roothypocotyl axis (up to the distance of $1.5 \mathrm{~mm}$ from radical tip), because we demonstrated that the accumulating ROS that spread from the root cap to the root apical meristem in embryonic axes of $F$. sylvatica seeds are key factors that affect the success of long-term storage (unpublished data) as well as Brassica napus root is the most susceptible tissue to water deficit stress soon after germination (BagniewskaZadworna 2008). Ultrathin sections on nickel grids were blocked in PBS/2 \% skim milk for 15 min at room temperature and were then incubated on a drop of primary antibody (raised against the dehydrin consensus K-segment (Close and others 1993), 1:100) in PBS/2 \% skim milk overnight at $4{ }^{\circ} \mathrm{C}$ in a humid chamber. After careful washing in PBS, the sections were incubated with $15 \mathrm{~nm}$ gold-labeled goat anti-rabbit secondary antibody diluted 1:20 in PBS/ $1 \%$ skim milk at $37^{\circ} \mathrm{C}$ for $2 \mathrm{~h}$. Subsequently, the sections were washed with PBS and rinsed with distilled water. The experiment was also performed without primary antibodies to assess the specificity of labeling. Sections were examined with a JEM 1200 EX II (Jeol, Tokyo, Japan) transmission electron microscope. On average, 5 different grids from each experimental variant were investigated.

\section{Statistical Analysis}

Data are presented as the mean \pm standard deviation of 3 biological replicates. The significant differences between particular parameters were tested using a correlation coefficient analysis. The significance among the means of components (between-group component and within-group component) was verified by $F$ test at $P<0.05$, and significantly different values are marked with different letters in the graph. 
Fig. 1 The water content and dry mass accumulation of embryonic axes of beech seeds during maturation time between the 12th and 19th week after flowering (WAF). Water content is calculated as the dry weight basis and presented as a percentage. Dry mass accumulation is presented with $\left[\mathrm{g} * \mathrm{~g}^{-1}\right]$ units referring to dry weight [g] divided by $\mathrm{H}_{2} \mathrm{O}[\mathrm{g}]$. Presented data are the means of three independent replicates, \pm SD

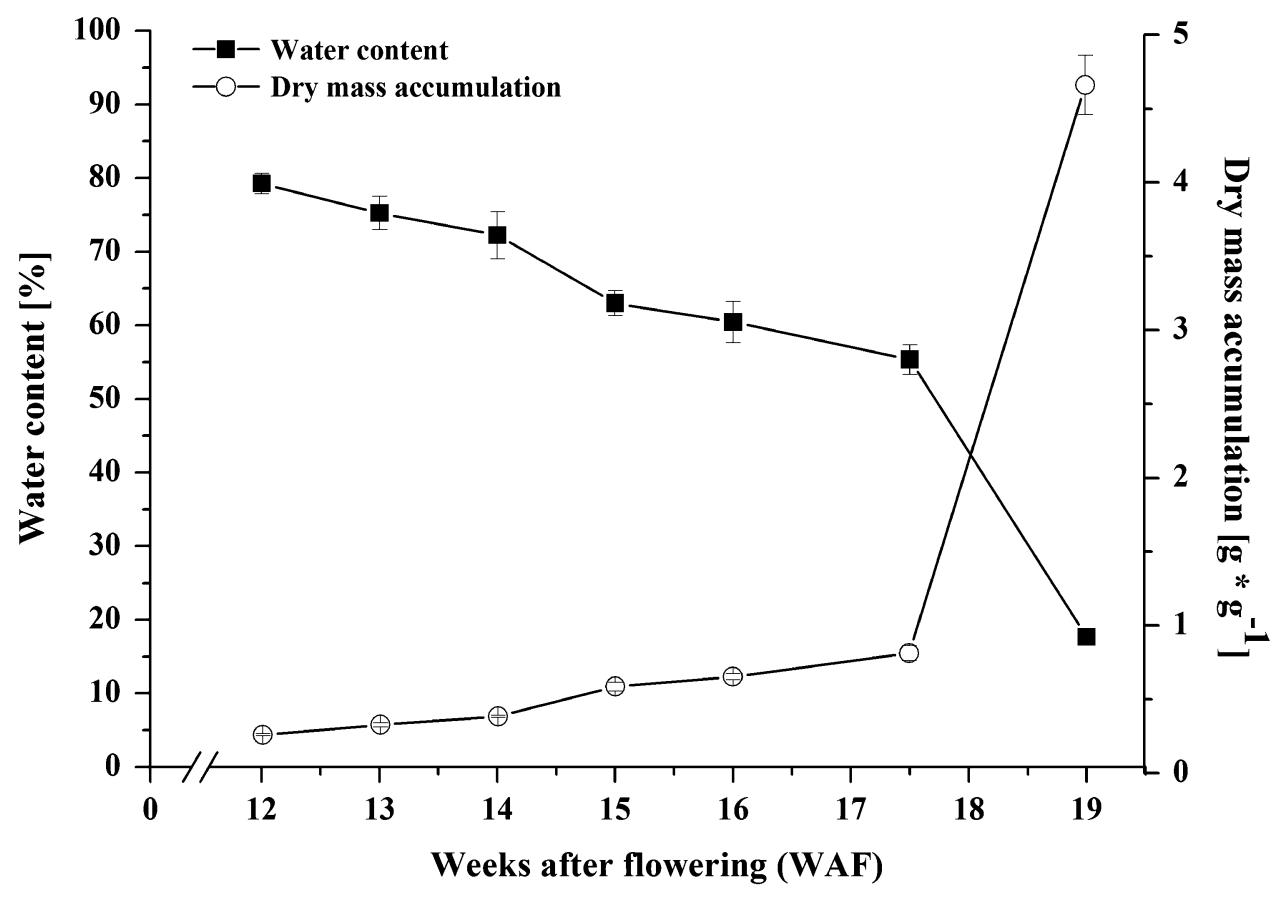

Bioinformatic Tools

The ability of dehydrin proteins to interact with DNA was investigated using the DIsis (http://cubic.bioc.columbia. edu/services/disis; Ofran and others 2007) and DP-Bind (http://lcg.rit.albany.edu/dp-bind/; Hwang and others 2007) programs using the dehydrin protein sequence named dehydrin/response ABA protein from $F$. sylvatica with accession number CAE54590.1 (Jiménez and others 2008) as the query. The Profisis (ISIS) program was run at the PredictProtein server (https://www.predictprotein.org/; Ofran and Rost 2006) to predict possible sites of dehydrinprotein interactions. Monte Carlo simulations of helical peptides in association with lipid membranes were made using the MCPep server (http://bental.tau.ac.il/MCPep/; Gautier and others 2008).

\section{Results}

\section{Water Content}

The embryonic axes of beech ( $F$. sylvatica L.) seeds were analyzed during their maturation between the 12th and 19th WAF, and the water content (dry weight basis) and dry weight were determined (Fig. 1). The water content at the 12th WAF was high and reached $80 \%$; however, after 16 weeks of maturation, the water content decreased to approximately $18 \%$ (at 19th WAF) because of the dry mass accumulation.
Expression and Characterization of Dehydrin-like Proteins

Three dehydrin-like proteins were detected in protein extracts of common beech ( $F$. sylvatica L.) embryonic axes during seed maturation beginning from the 12th up to the 19th WAF (Fig. 2a). Soluble protein extracts were used for comparison with the immunocytochemistry data, which were generated using whole embryonic axes containing all protein fractions. However, in previous analyses, we had determined that in stored beech seeds, the 26 and $44 \mathrm{kDa}$ dehydrins were heat-stable, and the $37 \mathrm{kDa}$ protein was more sensitive to high temperatures (Kalemba and Pukacka 2008). The $44 \mathrm{kDa}$ protein was the most abundant dehydrin during seed development and was clearly detectable since 14th WAF. Then, at the 16 th WAF, the $44 \mathrm{kDa}$ protein content increased, and progressive accumulation was observed until the end of maturation (Fig. 2a). The protein band corresponding to the $44 \mathrm{kDa}$ dehydrin was analyzed densitometrically (Fig. 2b) and was compared with the water content data (Fig. 1). The correlation coefficient $(r=-0.9046)$ indicated a statistically significant relationship between the $44 \mathrm{kDa}$ dehydrin level and water content in embryonic axes, while the $P$ value equaled 0.0051 indicating that the waterrelated expression of the $44 \mathrm{kDa}$ dehydrin is important for the seed developmental process. The $26 \mathrm{kDa}$ dehydrin protein was noted at the end of the seed maturation time and gave a weak protein band (Fig. 2a). Conversely, the dehydrin-like protein with an approximately $37 \mathrm{kDa}$ molecular weight was present throughout the time of maturation and its concentration remained relatively unchanged. Interestingly, we 
A
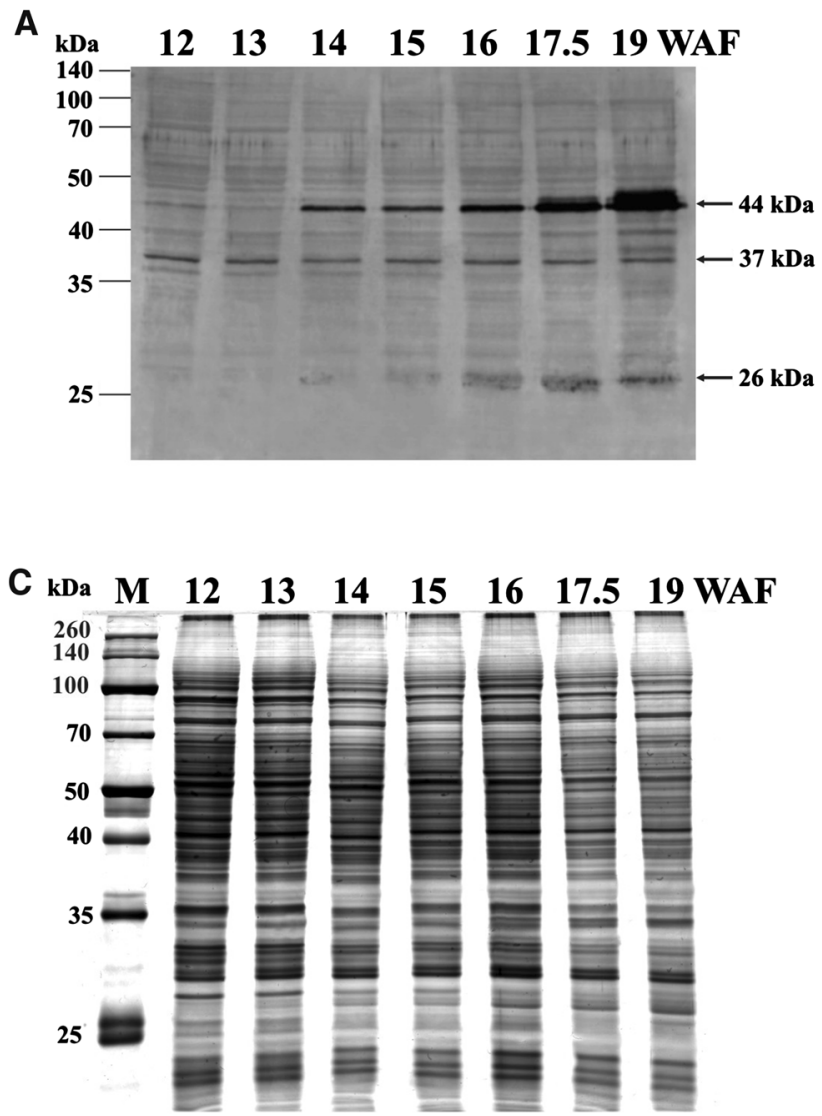

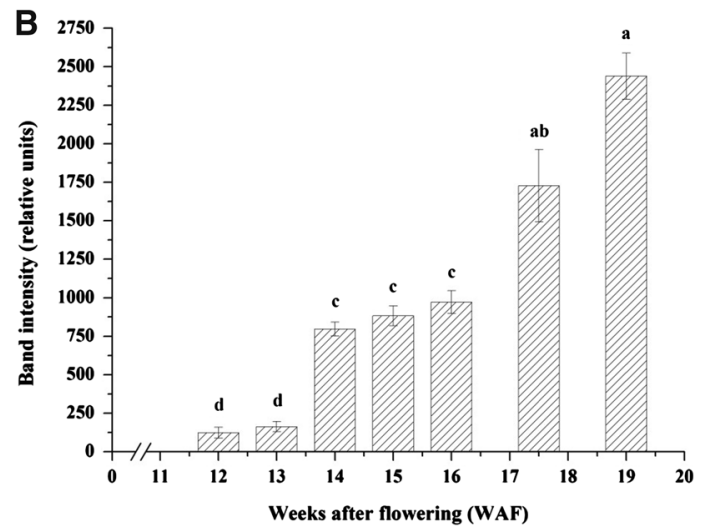

$D_{\text {kDa }}$

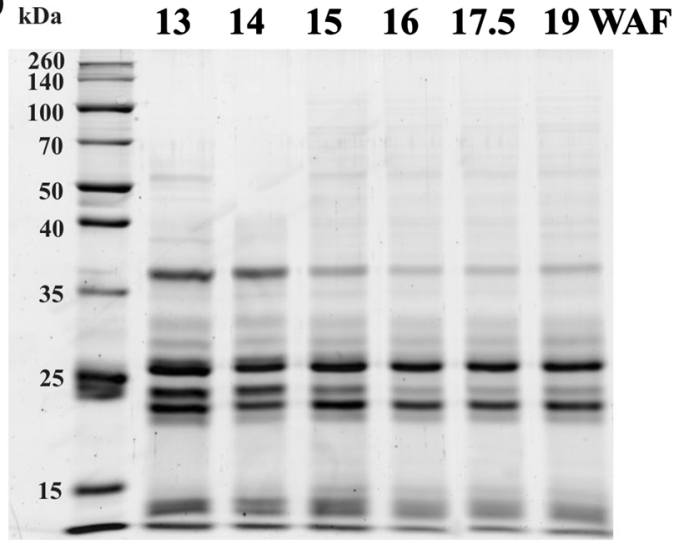

E 44 kDa

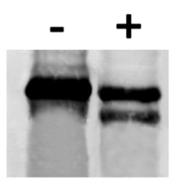

37 kDa

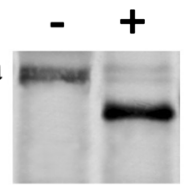

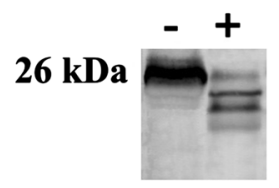

Fig. 2 Detection of dehydrin-like proteins in the embryonic axes of beech (Fagus sylvatica L.) seeds during maturation using an antibody specific to the K-segment (a). The dehydrins and dehydrin-like proteins were compared to soluble protein extracts resolved using a $12 \%$ polyacrylamide gel and stained with silver (c). Intensities of the $44 \mathrm{kDa}$ dehydrin signal are shown in the graph (b). Phosphorylated soluble proteins were visualized with Pro-Q ${ }^{\circledR}$ Diamond staining (d).
Phosphorylation was examined by enzymatic reaction with phosphatase $(+)$ and then compared to non treated protein extracts $(-)$ using the Western blot method (e), a representative dephosphorylation experiment is shown. Three independent biological repetitions were performed for each analysis. The Spectra Multicolor Broad Range Protein Ladder (Fermentas) molecular mass marker (M) was used reported the accumulation of a $26 \mathrm{kDa}$ protein in the soluble fraction (Fig. 2c), which appeared to be a legumin-type storage protein (identified with the Edman degradation method) that co-migrates with the $26 \mathrm{kDa}$ dehydrin and masks detection of the dehydrin using Western blot analyses (Fig. 2a).

Soluble protein extracts representing subsequent stages of seed development and maturation (Fig. 2c) were analyzed according to the presence of post-translational phosphorylation (Fig. 2d). None of the three detected dehydrins (Fig. 2a) appeared to be heavily phosphorylated during seed development. Proteins with approximate molecular weights of 23 and $26 \mathrm{kDa}$ seem to be the most abundant phosphoproteins. These phosphoproteins are present during all developmental stages at relatively unchanged levels, which exclude the possibility that the $26 \mathrm{kDa}$ phosphoprotein is the dehydrin-like protein. The possibility of protein phosphorylation was examined for all detected dehydrin-like proteins, and all of them appear to be phosphorylated (Fig. 2e) because their molecular weight decreased after dephosphorylation. A representative dephosphorylation experiment is shown because during all the seed maturation period investigated and in dry seeds similar patterns of protein bands were reported. 

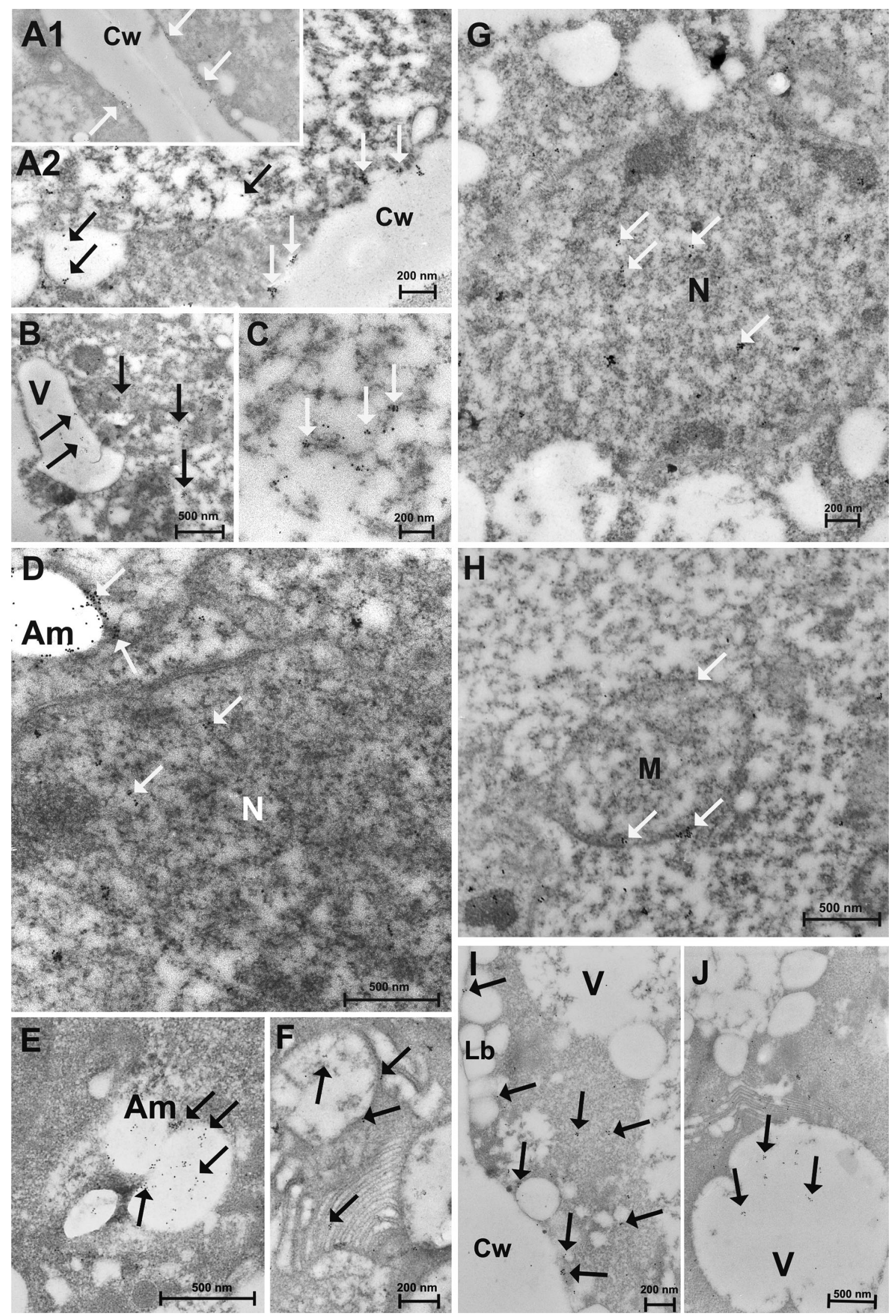
4Fig. 3 Dehydrin-like protein localization in the embryonic axes of common beech (Fagus sylvatica L.) seeds during development between the 12th and 19th week after flowering. Representative images of subcellular localization from different cell compartments are presented. Using antibody specific to K-segment, dehydrins were localized along the plasma membrane (a), inside cytoplasmic vesicles or small vacuoles $(\mathbf{b}, \mathbf{c})$, associated with the amyloplast matrix, envelope, and starch grains $(\mathbf{d}, \mathbf{e})$, and membranous structures $(\mathbf{f})$, inside the nucleus $(\mathbf{d}, \mathbf{g})$, attached to the mitochondrial envelope (h), throughout the cytoplasm (i), and inside larger, possibly developing storage vacuoles (j). Dehydrin-like proteins are detected with gold particles indicated by arrows. $V$ vacuole, $A m$ amyloplast, $N$ nucleus, $M$ mitochondria, $C w$ cell wall, $L b$ lipid bodies. To be consistent with the developmental embryo stage from particular images description: 13WAF (A1, B, D, H); 15WAF (C,E,F); 16WAF (A2, G); 17,5WAF (I, J)

\section{Immunolocalization of Dehydrin-like Proteins}

Immunolocalization of dehydrin-like proteins was performed on the embryonic axes of common beech $(F$. sylvatica $\mathrm{L}$.) seeds. Subcellular localizations were analyzed in maturating seeds and dry-stored seeds with antibody specific to dehydrin K-segment. There were no specific dehydrin localizations associated with specific beech seed developmental stages, and there were no differences at the subcellular level in all analyzed tissues from root-hypocotyl axis; however, for this work we focused on the cortical region. All of the examined subcellular localizations were positive for dehydrins throughout all of the seed maturation time points beginning at the 12th up to the 19th WAF. Dehydrin-like proteins were frequently detected along the plasma membrane in the close vicinity to the cell wall (Fig. 3a). In many cells, dehydrin-like proteins were observed as associated with small cytoplasmic structures and attached to vesicles located near cell plasma membrane or were frequently noticed inside those vesicles or in the small vacuoles (Fig. 3a, b, c, f). Moreover, dehydrins appeared to be associated with amyloplasts, being detectable in the developing starch grains, plastid matrix and a lesser extent attached to envelopes (Fig. 3d, e). Amyloplasts were mostly found during seed maturation, and consisted of few smaller size starch grains, especially closer to the radical tip. In general, dehydrins were linked to various membrane structures (Fig. 3f). Specific signals inside the nucleus and their association with scattered chromatin (Fig. $3 \mathrm{~g}$ ) pointed to nuclear localization of dehydrin-like proteins. Dehydrin-like proteins were attached to the mitochondrial envelope (Fig. 3h) and were identified throughout the cytoplasm, especially in the electron dense areas and in the vicinity of lipid bodies and vesicles, located along or close to cell walls (Fig. 3i) and in the larger vacuoles, which are supposed to be developing protein storage vacuoles (Fig. 3j).

Subcellular localization was also investigated in the embryonic axes of stored beech seeds. For this experiment, 2-years-stored seeds were used, and at this time, fewer specific localizations were found in the dry seed tissues. Dehydrin-like proteins were found mostly inside the amyloplasts, containing from one to three large starch grains per section (Fig. 4a, c). At a greater distance from the radical tip, cortex cells from hypocotyls contained large, mostly simple amyloplasts that also showed a dehydrin positive reaction. Slight dehydrin localization was noticed in the nuclei and cytoplasmic vesicles (Fig. 4b). The dehydrin localization was occasionally detected inside the vacuoles with dispersed electron dense content, cytoplasm or the plasma membrane, and membranous structures as single gold particles (Fig. 4b, d).

Before the determination of the subcellular locations of dehydrins, to clearly recognize the analyzed structures, we used TEM images after osmium tetroxide treatment and after embedding the material in Spurr's resin (Fig. 5a-d). The material was analyzed from the radical tips to the hypocotyls. The results of the control reaction to assess the specificity of labeling were negative (Fig. 5e-h); we did not observe any gold particles in the structure analyzed.

\section{Prediction of Possible Dehydrin Interactions}

Dehydrin/response ABA protein from $F$. sylvatica with accession number CAE54590.1 (Jiménez and others 2008) and dehydrin, partial from $F$. sylvatica with accession number CBY89194.1 (unpublished data) are the only accessible dehydrin sequences in public databases from beech seeds. Using the full dehydrin/response ABA protein sequence as a query, the ability of dehydrin protein to interact with DNA was investigated with the DIsis program. The RKKK residues at position 124-127 were indicated as the most probable sites of interaction. The DPBIND program indicated 5 amino acid tracks, including the RKKK sequence, and 12 single amino acids (Supplementary Table 1) with the highest probability of interaction with DNA. The Profisis program was used to predict 12 potential sites of dehydrin-protein interactions (Supplementary Fig. 1), and 5 of them were represented by tracks of 4-16 amino acids. Based on the amino acid sequence, dehydrin/response ABA protein (CAE54590.1) has a $12.5 \%$ glycine content, which indicates it is a highly hydrophilic protein.

Monte Carlo simulations of helical peptides in association with lipid membranes were performed using the MCPep server to predict putative dehydrin-lipid interactions (Supplementary Fig. 2). Three 50 amino acid dehydrin (CAE54590.1) peptides were analyzed, and two of them contained the consensus K-segment, which potentially forms an amphipathic helix, and one $\mathrm{N}^{\prime}$-terminal peptide containing no consensus dehydrin segments as a reference probe. Two peptides, each containing the 

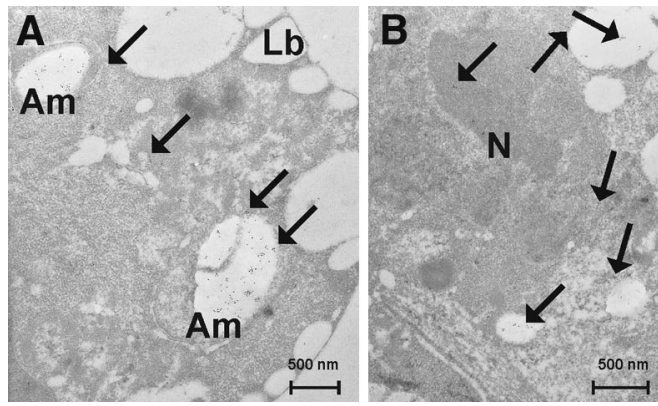

Fig. 4 Dehydrin-like protein localization in the embryonic axes of beech seeds stored for 2 years. Using antibody specific to K-segment, dehydrins were identified (arrows) inside the amyloplasts (a, c), in the

consensus K-segment, were predicted to interact with membranes based on the average distance of each residue from the membrane midplane and the capacity to stay in a water solution (Supplementary Fig. 2a-d). Simulations of the $\mathrm{N}^{\prime}$-terminal peptide of dehydrin showed that it does not interact with membranes but stays in water solutions (Supplementary Fig. 2e, f). Moreover, it was predicted that the peptide containing the K-segment in position 125-140 may be closer in proximity $(20 \AA)$ to the phosphate groups of the lipid polar heads than the peptide containing the K-segment in positions 168-182 (40 A) (Supplementary Fig. $2 \mathrm{~g}$ ).

\section{Discussion}

Accumulation of the $44 \mathrm{kDa}$ dehydrin was previously assumed to be an important embryogenesis program element associated with the acquisition of desiccation tolerance during beech seed development (Kalemba and others 2009). This protein was the most abundant among all detected dehydrin-like proteins (Fig. 2a). At $19 \mathrm{WAF}$, the concentration of the $44 \mathrm{kDa}$ dehydrin increased over 15 times compared to the initial level (12-13 WAF), and the increase was strongly negatively correlated with the water content of embryonic axes (Fig. 1). Dehydrins are a multifamily of plant proteins related to embryogenesis, and they accumulate under water stress conditions (Rorat 2006; Battaglia and others 2008; Hara 2010; Battaglia and Covarrubias 2013). Preferential hydration of diverse molecules and water replacement in dehydrated cells is performed by dehydrins to maintain structural stabilization (Hoekstra and others 2001), including during the development and maturation of seeds (Panza and others 2007).

Nuclear localization, particularly in the segmented nuclei, irregular in shape and characteristic of maturating cells, was reported in the embryonic axes of developing beech seeds. This finding indicated the importance of dehydrin-like proteins in the protection of nuclear processes

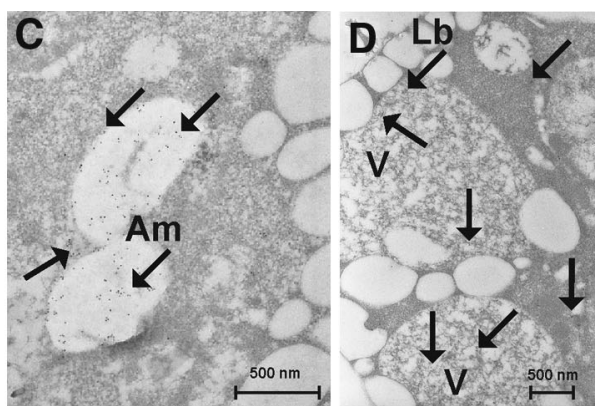

nuclei (b), and associated with vesicles and vacuoles with dispersed electron dense content $(\mathbf{b}, \mathbf{d})$. $A m$ amyloplast, $N$ nucleus, $L b$ lipid bodies

because they were associated with scattered chromatin. Dehydrins were previously found to be associated with chromatin in the nucleus of $A$. angustifolia (Bert.) O. Kuntze embryos (Farias-Soares and others 2013) and mature Euterpe edulis Martius seeds (Panza and others 2007). The dehydrins possibly participated in protection of the transcriptional machinery enabling the realization of the seed developmental program (Panza and others 2007; FariasSoares and others 2013) by induction and maintenance of embryogenesis (Burrieza and others 2012). DehydrinDNA interaction may stabilize the DNA conformation in the nucleus during seed maturation under extreme dehydration (Lin and others 2012), specifically when strongly labeled areas contain dispersed chromatin (Houde and others 1995). Contrary to developing seeds in the embryonic axes of dry, stored beech seeds, we observed only slight dehydrin localization in the nuclei (Fig. 4b). This appears to be common as little dehydrin labeling was detected in nuclear areas containing dense chromatin (Houde and others 1995; Carjuzaa and others 2008).

The Y-segment was thought to be a putative nucleotidebinding domain (Close 1996). Using accessible beech dehydrin sequences, we predicted that at least one dehydrin has the ability to interact with DNA through the RKKK residues, which is the motif that resembles the SV40-like NLS sequence (K-R/K-X-K/R), and several other single or neighboring amino acids including a part of Y-segment sequences (Supplementary Table 1). DNA-binding activity of the RKKK residues was proposed by the DIsis and DPBind programs and was demonstrated experimentally by Yen and others (1998), which makes it highly probable that there is a DNA-binding site in dehydrin proteins. Yen and others (1998) reported that the RKKK sequence was critical for high-affinity DNA association. Dehydrins, which lack the nuclear localization signal, were also found in the nucleus (Houde and others 1995; Wisniewski and others 1999) indicating that nuclear localization is not always the final destination of dehydrin proteins. Co-transport to the nucleus through protein-protein interaction may explain 

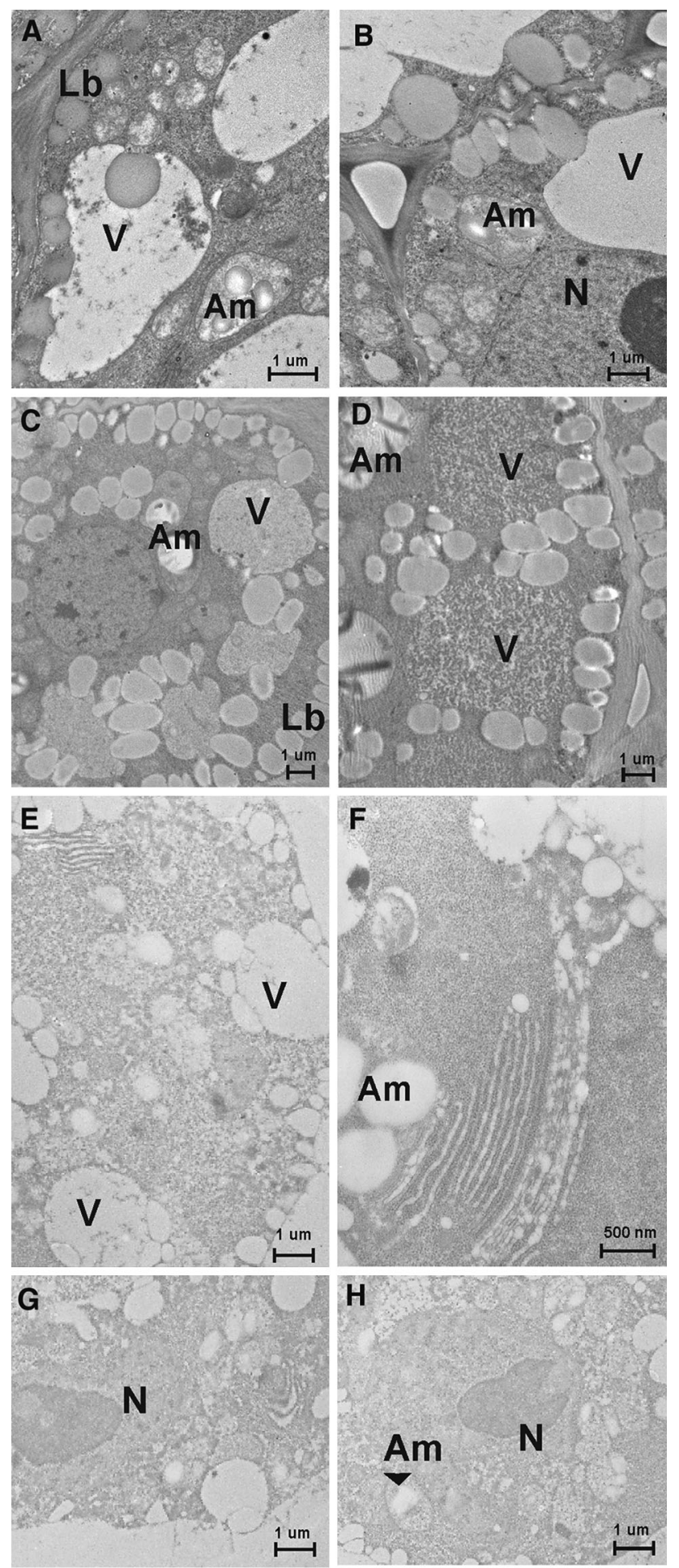

Fig. 5 Ultrastructure of the embryonic axes of beech seeds (material after osmium tetroxide post-fixation and Spurr's resin embedding, ad) and negative results of control reactions $(\mathbf{e}-\mathbf{h}) . A m$ amyloplast, $N$ nucleus, $V$ vacuole, $L b$ lipid bodies

the nuclear localization of dehydrins (Houde and others 1995). Conversely, nucleus-targeted proteins, including dehydrins containing the RKKK motif, may function as nuclear import/export carriers (Godoy and others 1994). This function of dehydrin-protein interactions may be made possible through the predicted amino acid tracks (Supplementary Fig. 1) given the probability of interactions with various types of protein domains and motifs even when dehydrin-protein interactions are labile (Danyluk and others 1998; Heyen and others 2002). Jensen and others (1998) demonstrated that phosphorylation of the Rab17 dehydrin protein by CK2 kinase is an essential step for its nuclear location. Moreover, Rab17 was the most heavily phosphorylated protein in the mature maize embryo (Godoy and others 1994). Our results showed that two phosphoproteins dominate during beech seed development (Fig. 2d). Although dehydrins were not the most highly phosphorylated proteins, it is likely that all detected dehydrin-like proteins (Fig. 2a) contained polyserine segments and were present in seeds in their phosphorylated forms (Fig. 2e), which is the major post-translational modification and is required for protein function (Brini and others 2007). Dehydrin protein (CAE54590.1) was classified in the $\mathrm{Y}_{\mathrm{n}} \mathrm{SK}_{2}$ group (Jiménez and others 2008), and its molecular mass predicted from the amino acid sequence is similar to the molecular weight of the $26 \mathrm{kDa}$ dehydrin after enzymatic dephosphorylation (Fig. 2e). The band pattern after dephosphorylation indicates that this protein may comprise several phosphorylation states (Jensen and others 1998) related to numerous serine residues in the sequence (Jiménez and others 2008).

It has been demonstrated that water removal initiates contacts between dehydrins and membrane lipids (Danyluk and others 1998). Cell membranes are regarded as the main site of desiccation injury because disorganization of membranes apparently results in enhanced permeability. In maturating beech seeds, electrolyte leakage was 4-6 times higher at 12 and 14 WAF, which is before the acquisition of desiccation tolerance (Kalemba and others 2009). At this time, a high water content (Fig. 1) and only the $37 \mathrm{kDa}$ dehydrin-like protein were detected (Fig. 2). At the 16th WAF, increased 26 and $44 \mathrm{kDa}$ dehydrin levels (Fig. 2a, b) were linked with lowered electrolyte leakage (Kalemba and others 2009). This observation may be linked to the plasma membrane localization of dehydrin-like proteins after protein accumulation (Fig. 2a). For dehydrin-membrane interactions, it is unknown whether membrane lipids or membrane proteins are the main target. However, beech dehydrin protein was predicted to interact with other proteins (Supplementary Fig. 1) and lipid membranes (Supplementary Fig. 2). Dehydrins are peripheral proteins (Danyluk and others 1998) and can function as dimers (Lin and others 2012). The lack of certain tertiary structures in dehydrins additionally favors the potential of such interactions (Kovacs and others 2008). Koag and others (2003) suggested that dehydrin function may be related to their 
membrane targets as nearly all of the structure gained by dehydrins upon binding to small uni-lamellar vesicles (containing acidic phospholipids) were $\alpha$-helical. Dehydrin association with the cell membrane may be explained by the fact that dehydrins can favorably bind to lipid vesicles of smaller diameters (Koag and others 2003). The K-segment is predicted to interact with membranes by forming an amphipathic $\alpha$-helix (Close 1996; Koag and others 2009), which is required for binding to anionic phospholipid vesicles (Koag and others 2009). All detected dehydrin-like proteins contained at least one K-segment (Fig. 2a); therefore, their possible association with membranes through $\mathrm{K}$-segments is likely (Supplementary Fig. 2).The endomembrane system in plant cells has a complex organization (Ebine and others 2008). The dehydrin-like proteins associated with small vesicles located near the cell membrane and small structures throughout the cytoplasm may participate in cellular transport and membrane fusion, including protein transport into forming protein storage vacuoles (Chrispeels 1985). The protein inclusions inside storage vacuoles were also observed in this work (Fig. 5a), thus possibly some of the vesicles with dehydrins detected are suspected to be transported into storage vacuoles. Accumulation of dehydrin proteins near membranes and/or cell walls during osmotic stress is a well-known phenomenon not only in plants but also in the moss Physcomitrella patens (Ruibal and others 2012) and the fern Polypodium polypodioides (Layton and others 2010). Accumulation of WCOR410 proteins in the vicinity of the plasma membrane of cold-acclimated wheat cultivars suggested that they were involved in the cryoprotection of the plasma membrane against freezing or dehydration stress (Danyluk and others 1998). In contrast, Borovskii and others (2005) established that during autumnal hardening or adaptation to low temperature, dehydrins were bound to the outer mitochondrial membrane in wheat crowns. In our studies, dehydrins were identified as associated with the mitochondrial envelope, possibly both on the inner and outer sides, in a manner unrelated to low temperature. For instance, constitutive accumulation of putative dehydrins in the mitochondrial matrix of lupin seeds was possibly related to the protection of important soluble mitochondrial enzymes (Rurek 2010). It would be interesting if dehydrins could neutralize cellular oxidative stress acting at the border of mitochondria, the main reactive oxygen species source, and at the cytoplasm specifically when the mitochondria are intensively producing energy during seed development. This antioxidant hypothesis of some types of dehydrins is supported by the results showing that dehydrin protein prevented peroxidation of liposomes in vitro (Hara and others 2003) and disrupted DrpA (dehydrin-like gene) mutants of Aspergillus fumigates that were hypersensitive to oxidative stress
(Wong Sak Hoi and others 2011). Therefore, dehydrin-like proteins may act as radical-scavenging molecules (Hara and others 2003) that protect mitochondrial membranes under stress and may be involved in the control of the physiochemical status of mitochondrial membranes (Rurek 2010).

The unique amyloplast localization of dehydrins in the embryonic axes of maturating and stronger accumulation in dry-stored beech seeds exemplifies the fact that dehydrin subtypes can accomplish their function in different cell compartments (Danyluk and others 1998; Vornam and others 2011). In non-cold-acclimated apices of birch, dehydrins were present only in the cytoplasm, whereas in cold-acclimated plants, dehydrins were detected in nuclei and storage protein bodies (Rinne and others 1999). In birch, dehydrin production in the apices is accompanied by starch grain production, and dehydrins were strongly accumulated in starch-rich amyloplasts (Rinne and others 1999). Similarly, in cold-acclimated wheat plants, dehydrins were located preferentially at the plasma membrane lining, and at the same time, no labeling was detected in the cytoplasm, nucleus, organelles, or vacuoles (Danyluk and others 1998) confirming that one single dehydrin location may occur under specific conditions. Dry embryonic axes of beech seeds contained no more than $10 \%$ water and thus consist of desiccated tissue. Recently, it was shown that dehydrins play a role in desiccation tolerance (Wang and others 2012), and this function is conserved in stored beech seeds (Kalemba and Pukacka 2014). Dehydrins associated with amyloplasts may act by rescuing enzyme functions in key metabolic processes during dehydration. These enzyme functions are required for survival and regrowth by creating a local pool of water in dehydrated cells (Rinne and others 1999; Jiang and others 2001). The rescue of enzyme functions by dehydrins during dormancy alleviation and germination of beech seeds enables starch utilization enzymes to function, which creates an early energy source. Dehydrins associated with amyloplasts (Fig. 4a, c), protein storage vacuoles (Rinne and others 1999), and lipid bodies (Egerton-Warburton and others 1997) emphasize the significant roles of dehydrin in storage reserve accumulation and subsequent consumption. The buffering of digestive enzymes early in germination by dehydrins is important, as protein bodies were noted to be directly involved in storage lipid mobilization during seed germination by shifting lytic enzymes from protein bodies to the cytoplasm and the surface of the oil bodies after seed imbibition (Zienkiewicz and others 2014).

At some stage of desiccation after the loss of structural water, important processes such as water replacement and glassy structure formation are initiated (Hoekstra and others 2001). LEA proteins participate in all of these processes and lead to water deficit tolerance expansion by acting as a hydration buffer (Sivamani and others 2000). Additionally, 
LEA proteins increase the glass transition temperature and the strength of hydrogen bonds of the glass matrix (Wolkers and others 2001). It was shown that after desiccation in the embryonic axes of beech seeds, the glassy state is formed in the cytoplasm (Pukacka and others 2003). However, the cytoplasmic localization of dehydrins in the dry state was not reported. This is curious because at least one beech dehydrin (CAE54590.1) is highly hydrophilic because a protein can be classified as hydrophilic, when the glycine content is above $6 \%$ (Battaglia and others 2008). However, this does not exclude the possible action of dehydrin-like proteins in glassy state formation even if they are not present in the matrix structure.

Egerton-Warburton and others (1997), investigating embryo tissue of Zea mays L. kernels, stated that the primary function of dehydrins involves the cytosol and the structures contained therein. After analyzing all published data presenting the different subcellular immunolocalizations of dehydrins, it can be hypothesized that dehydrins are easily transported throughout the cell, and their destination is variable and depends on the cell water state, stage of development, and many genetic and environmental factors. Afterward, dehydrins are recruited to ameliorate different stress effects (Rorat 2006; Battaglia and others 2008; Hara 2010; Battaglia and Covarrubias 2013) including plant-pathogen interaction (Zhai and others 2011) as rice dehydrin (specifically K-segment) exhibited antibacterial activities against Gram-positive bacteria. The highest density of gold particles was found inside vacuoles. VCaB45, a phosphorylated $45 \mathrm{kDa}$ calcium-binding dehydrin containing the K-segment, was located within the lumen of vacuoles (Heyen and others 2002). It was proposed that VcaB45 plays a calcium-dependent protein chaperone role similar to the function of calnexin and calreticulin. In our studies, ion binding activity was not analyzed. However, dehydrin-like proteins may act as chaperones to molecules deposed in the vacuole during the maturation of beech seeds.

\section{Conclusion}

It has been established that LEA proteins accumulate in high concentrations in embryo tissues during the last stages of seed development before desiccation, and specifically, dehydrins are regulators of cellular osmotic potential. In our research, dehydrin-like proteins have been localized in various cell parts and organelles during seed developmental stages and when seeds were desiccated and stored. These findings highlight that particular molecules, organelles, or biological processes have to be protected during different seed developmental stages. Dehydrin-like proteins appear to be involved in the reduction of desiccation- induced cellular damage of the plasma membrane, organelle membranes, nucleus, and storage material reservoirs. Dehydrins most likely also assist and are a part of vesiclemediated cellular transport during seed development and assist in storage material degradation early in germination, which emphasizes their ability to associate with lipids and cell membranes, consisted of the phospholipid bilayer with embedded proteins. However, dehydrin-membrane interactions are of particular interest for future investigation because, apart from plasma membrane and membrane structure localizations, dehydrin-like proteins were associated with organelle membranes and found within organelles, and they displayed a linear pattern. Potential membrane-associated dehydrin-like protein partner interactors, predicted with in silico analyses, are still unknown. This is a notable research area requiring future investigation to elucidate the mechanism of dehydrin chaperone activity.

Acknowledgments The antisera raised against the K-segment was kindly supplied by T.J. Close, Department of Botany and Plant Sciences, University of California, Riverside, CA, USA. This research was supported by The Ministry of Science and Higher Education (Poland)/National Centre of Sciences (Poland)-Grant no. N N309 136535. Fluorescent gel scans were performed in Proteomic Laboratory, where the Ettan DIGE Imager device was purchased with funds provided by The National Centre for Research and Development, Grant no. 14005806.

Conflict of interest The authors declare that they have no conflict of interest.

Open Access This article is distributed under the terms of the Creative Commons Attribution License which permits any use, distribution, and reproduction in any medium, provided the original author(s) and the source are credited.

\section{References}

Asghar R, Fenton RD, Demason DA, Close TJ (1994) Nuclear and cytoplasmic localization of maize embryo and aleurone dehydrin. Protoplasma 177(3-4):87-94

Bagniewska-Zadworna A (2008) The root microtubule cytoskeleton and cell cycle analysis through desiccation of Brassica napus seedlings. Protoplasma 233:177-185

Bagniewska-Zadworna A, Wojciechowicz MK, Zenkteler M, Jeżowski S, Zenkteler E (2010) Cytological analysis of hybrid embryos of intergeneric crosses between Salix viminalis and Populus species. Aust J Bot 58:42-48

Battaglia M, Covarrubias AA (2013) Late embryogenesis abundant (LEA) proteins in legumes. Front Plant Sci 4:190

Battaglia M, Olvera-Carrillo Y, Garciarrubio A, Campos F, Covarrubias AA (2008) The enigmatic LEA proteins and other hydrophilins. Plant Physiol 148:6-24

Bonner FT (1990) Storage of seeds: potential and limitations for germplasm conservation. For Ecol Manag 35:35-43

Borovskii GB, Stupnikova IV, Antipina AI, Anuchina OS, Voinikov VK (2005) Association of dehydrins with wheat mitochondria 
during low-temperature adaptation. Russ J Plant Physiol 52:194-198

Bradford MM (1976) A rapid and sensitive method for the quantitation of microgram quantities utilizing the principle of protein dye binding. Anal Biochem 72:248-254

Brini F, Hanin M, Lumbreras V, Irar S, Pagès M, Masmoudi K (2007) Functional characterization of DHN-5, a dehydrin showing a differential phosphorylation pattern in two Tunisian durum wheat (Triticum durum Desf.) varieties with marked differences in salt and drought tolerance. Plant Sci 172(1):20-28

Burrieza HP, López-Fernández MP, Chiquieri TB, Silveira V, Maldonado S (2012) Accumulation pattern of dehydrins during sugarcane (var. SP80.3280) somatic embryogenesis. Plant Cell Rep 31(12):2139-2149

Carjuzaa P, Castellión M, Distéfano AJ, del Vas M, Maldonado S (2008) Detection and subcellular localization of dehydrin-like proteins in quinoa (Chenopodium quinoa Willd.) embryos. Protoplasma 233(1-2):149-156

Chrispeels MJ (1985) The role of the Golgi apparatus in the transport and post-translational modification of vacuolar (protein body) proteins. Plant Mol Cell Biol 2:43-68

Close TJ (1996) Dehydrins: emergence of a biochemical role of a family of plant dehydration proteins. Physiol Plant 97:795-803

Close TJ (1997) Dehydrins: a commonalty in the response of plants to dehydration and low temperature. Physiol Plant 100(2):291-296

Close TJ, Fenton RD, Moonan F (1993) A view of plant dehydrins using antibodies specific to the carboxy terminal peptide. Plant Mol Biol 23(2):279-286

Danyluk J, Perron A, Houde M, Limin A, Fowler B, Benhamou N, Sarhan F (1998) Accumulation of an acidic dehydrin in the vicinity of the plasma membrane during cold acclimation of wheat. Plant Cell 10:623-638

Ebine K, Okatani Y, Uemura T, Goh T, Shoda K, Niihama M, Morita MT, Spitzer C, Otegui MS, Nakano A, Ueda T (2008) A SNARE complex unique to seed plants is required for protein storage vacuole biogenesis and seed development of Arabidopsis thaliana. Plant Cell 20(11):3006-3021

Egerton-Warburton LM, Balsamo RA, Close TJ (1997) Temporal accumulation and ultrastructural localization of dehydrins in Zeamays. Physiol Plant 101:545-555

Ellis RH, Hong TD, Roberts EH (1990) An intermediate category of seed storage behaviour? J Exp Bot 41:1167-1174

Farias-Soares FL, Burrieza HP, Steiner N, Maldonado S, Guerra MP (2013) Immunoanalysis of dehydrins in Araucaria angustifolia embryos. Protoplasma 250(4):911-918

Finch-Savage WE, Pramanik SK, Bewley JD (1994) The expression of dehydrin proteins in desiccation-sensitive (recalcitrant) seeds of temperate trees. Planta 193:478-485

Garnczarska M, Zalewski T, Wojtyla $Ł$ (2008) A comparative study of water distribution and dehydrin protein localization in maturing pea seeds. J Plant Physiol 165(18):1940-1946

Gautier R, Douguet D, Antonny B, Drin G (2008) HELIQUEST: a web server to screen sequences with specific alpha-helical properties. Bioinformatics 24(18):2101-2102

Godoy JA, Lunar R, Torresschumann S, Moreno J, Rodrigo RM, Pintortoro JA (1994) Expression, tissue distribution and subcellular-localization of dehydrin Tas14 in salt-stressed tomato plants. Plant Mol Biol 26:1921-1934

Gosling PG (1991) Beechnuts storage: a review and practical interpretation of the scientific literature. Forestry 64:51-59

Goyal K, Walton LJ, Tunnacliffe A (2005) LEA proteins prevent protein aggregation due to water stress. Biochem J 388:151-157

Greggains V, Finch-Savage WE, Quick WP, Atherton NM (2000) Putative desiccation tolerance mechanisms in orthodox and recalcitrant seeds of genus Acer. Seed Sci Res 10:317-327
Hara M (2010) The multifunctionality of dehydrins: an overview. Plant Signal Behav 5(5):503-508

Hara M, Terashima S, Fukaya T, Kuboi T (2003) Enhancement of cold tolerance and inhibition of lipid peroxidation by citrus dehydrin in transgenic tobacco. Planta 217:290-298

Hara M, Fujinaga M, Kuboi T (2004) Radical scavenging activity and oxidative modification of citrus dehydrin. Plant Physiol Biochem 42:657-662

Heyen BJ, Alsheikh MK, Smith EA, Torvik CF, Seals DF, Randall SK (2002) The calcium-binding activity of a vacuole-associated, dehydrin-like protein is regulated by phosphorylation. Plant Physiol 130:675-687

Hoekstra FA, Golovina EA, Buitink J (2001) Mechanisms of plant desiccation tolerance. Trends Plant Sci 6(9):431-438

Houde M, Daniel C, Lachapelle M, Allard F, Laliberte S, Sarhan F (1995) Immunolocalization of freezing-tolerance-associated proteins in the cytoplasm and nucleoplasm of wheat crown tissues. Plant J 8:583-593

Hwang S, Gou Z, Kuznetsov IB (2007) DP-Bind: a web server for sequence-based prediction of DNA-binding residues in DNAbinding proteins. Bioinformatics 23(5):634-636

Jensen AB, Goday A, Figueras M, Jessop AC, Pages M (1998) Phosphorylation mediates the nuclear targeting of the maize Rab17 protein. Plant J 13:691-697

Jiang L, Phillips TE, Hamm CA, Drozdowicz YM, Rea PA, Maeshima M, Rogers SW, Rogers JC (2001) The protein storage vacuole: a unique compound organelle. J Cell Biol 155: 991-1002

Jiménez JA, Alonso-Ramírez A, Nicolás C (2008) Two cDNA clones (FsDhn1 and FsClo1) up-regulated by $\mathrm{ABA}$ are involved in drought responses in Fagus sylvatica L. seeds. J Plant Physiol 165:1798-1807

Kalemba EM, Pukacka S (2008) Changes in late embryogenesis abundant proteins and a small heat shock protein during storage of beech (Fagus sylvatica L.) seeds. Environ Exp Bot 63: 274-280

Kalemba EM, Pukacka S (2012) Association of protective proteins with dehydration and desiccation of orthodox and recalcitrant category seeds of three Acer genus species. J Plant Growth Regul 31:351-362

Kalemba EM, Pukacka S (2014) Carbonylated proteins accumulated as vitality decreases during long-term storage of beech (Fagus sylvatica $\mathrm{L}$.). Seeds 28(2):503-515

Kalemba EM, Janowiak F, Pukacka S (2009) Desiccation tolerance acquisition in developing beech (Fagus sylvatica L.) seeds: the contribution of dehydrin-like protein. Trees 23:305-315

Koag MC, Fenton RD, Wilkens S, Close TJ (2003) The binding of maize DHN1 to lipid vesicles. Gain of structure and lipid specificity. Plant Physiol 131:309-316

Koag MC, Wilkens S, Fenton RD, Resnik J, Vo E, Close TJ (2009) The K-segment of maize DHN1 mediates binding to anionic phospholipid vesicles and concomitant structural changes. Plant Physiol 150:1503-1514

Kovacs D, Kalmar E, Torok Z, Tompa P (2008) Chaperone activity of ERD10 and ERD14, two disordered stress related plant proteins. Plant Physiol 147:381-390

Laemmli UK (1970) Cleavage of structural proteins during the assembly of the head of bacteriophage T4. Nature 227:680-685

Layton BE, Boyd MB, Tripepi MS, Bitonti BM, Dollahon MN, Balsamo RA (2010) Dehydration-induced expression of a 31-kDa dehydrin in Polypodium polypodioides (Polypodiaceae) may enable large, reversible deformation of cell walls. Am J Bot 97(4):535-544

León-Lobos P, Ellis RH (2002) Seed storage behaviour of Fagus sylvatica and Fagus crenata. Seed Sci Res 12:31-37 
Lin CH, Peng PH, Ko CY, Markhart AH, Lin TY (2012) Characterization of a Novel Y2K-type dehydrin VrDhn1 from Vigna radiata. Plant Cell Physiol 53(5):930-942

Mueller JK, Heckathorn SA, Fernando D (2003) Identification of a chloroplast dehydrin in leaves of mature plants. Int J Plant Sci 164(4):5-42

Neven LG, Haskell DW, Hofig A, Li QB, Guy CL (1993) Characterization of a spinach gene responsive to low temperature and water stress. Plant Mol Biol 21(2):291-305

Nylander M, Svensson J, Palva ET, Welin BV (2001) Stress-induced accumulation and tissue specific localization of dehydrins in Arabidopsis thaliana. Plant Mol Biol 45:263-279

Ofran Y, Rost B (2006) ISIS: interaction sites identified from sequence. Bioinformatics 23:13-16

Ofran Y, Mysore V, Rost B (2007) Prediction of DNA-binding residues from sequence. Bioinformatics 23(13):347-353

Panza V, Distéfano AJ, Carjuzaa P, Láinez V, Del Vas M, Maldonado $S$ (2007) Detection of dehydrin-like proteins in embryos and endosperm of mature Euterpe edulis seeds. Protoplasma 231(1-2):1-5

Poulsen KM (1993) Predicting the storage life of beechnuts. Seed Sci Technol 21:327-337

Poulsen KM, Kundsen H (1999) Viability constants based on eight years storage of beech nuts (Fagus sylvatica L.). Seed Sci Technol 27:1037-1039

Pukacka S, Ratajczak E (2007) Age-related biochemical changes during storage of beech (Fagus sylvatica L.) seeds. Seed Sci Res $17: 45-53$

Pukacka S, Hoffmann SK, Goslar J, Pukacki PM, Wójkiewicz E (2003) Water and lipid relations in beech (Fagus sylvatica L.) seeds and its effect on storage behaviour. Biochim Biophys Acta 1621(1):48-56

Rinne PL, Kaikuranta PL, van der Plas LH, van der Schoot C (1999) Dehydrins in cold-acclimated apices of birch (Betula pubescens ehrh.): production, localization and potential role in rescuing enzyme function during dehydration. Planta 209(4):377-388

Roberts EH (1973) Predicting the storage life of seeds. Seed Sci Technol 1:499-514

Rorat T (2006) Plant dehydrins-tissue location, structure and function. Cell Mol Biol Lett 11:536-556

Ruibal C, Salamó IP, Carballo V, Castro A, Bentancor M, Borsani O, Szabados L, Vidal S (2012) Differential contribution of individual dehydrin genes from Physcomitrella patens to salt and osmotic stress tolerance. Plant Sci 190:89-102

Rurek M (2010) Diverse accumulation of several dehydrin-like proteins in cauliflower (Brassica oleracea var. botrytis), Arabidopsis thaliana and yellow lupin (Lupinus luteus) mitochondria under cold and heat stress. BMC Plant Biol 10:181
Sinha P, Poland J, Schnölzer M, Rabilloud T (2001) A new silver staining apparatus and procedure for matrix-assisted laser desorption/ionization-time of flight analysis of proteins after two-dimensional electrophoresis. Proteomics 1(7):835-840

Sivamani E, Bahieldrin A, Wraith JM, Al-Niemi T, Dyer WE, Ho TH, $\mathrm{Qu}$ R (2000) Improved biomass productivity and water use efficiency under water deficit conditions in transgenic wheat constitutively expressing the barley HVA1 gene. Plant Sci 155:1-9

Sunderlikova V, Salaj J, Kopecky D, Salaj T, Wilhelm E, Matusikova I (2009) Dehydrin genes and their expression in recalcitrant oak (Quercus robur) embryos. Plant Cell Rep 28:1011-1021

Tompa P, Csermely P (2004) The role of structural disorder in the function of RNA and protein chaperones. FASEB J 18(11): 1169-1175

Tunnacliffe A, Wise MJ (2007) The continuing conundrum of the LEA proteins. Naturwissenschaften 94:791-812

Vornam B, Gailing O, Derory J, Plomion C, Kremer A, Finkeldey R (2011) Characterisation and natural variation of a dehydrin gene in Quercus petraea (Matt.) Liebl. Plant Biol 13(6):881-887

Wang WQ, Møller IM, Song SQ (2012) Proteomic analysis of embryonic axis of Pisum sativum seeds during germination and identification of proteins associated with loss of desiccation tolerance. J Proteomics 77:68-86

Wisniewski M, Webb R, Balsamo R, Close TJ, Yu XM, Griffith M (1999) Purification, immunolocalization, cryoprotective and antifreeze activity of PCA60: a dehydrin from peach (Prunus persica). Physiol Plant 105:600-608

Wolkers WF, McCready S, Brandt WF, Lindsey GG, Hoekstra FA (2001) Isolation and characterization of a D-7 LEA protein from pollen that stabilizes glasses in vitro. Biochim Biophys Acta 1544:196-206

Wong Sak Hoi J, Lamarre C, Beau R, Meneau I, Berepiki A, Barre A, Mellado E, Read ND, Latgé JP (2011) A novel family of dehydrin-like proteins is involved in stress response in the human fungal pathogen Aspergillus fumigatus. Mol Biol Cell 22(11):1896-1906

Yen YM, Wong B, Johnson RC (1998) Determinants of DNA binding and bending by the Saccharomyces cerevisiae high mobility group protein NHP6A that are important for its biological activities. Role of the unique $\mathrm{N}$ terminus and putative intercalating methionine. J Biol Chem 273(8):4424-4435

Zhai C, Lan J, Wang H, Li L, Cheng X, Liu G (2011) Rice dehydrin $\mathrm{K}$-segments have in vitro antibacterial activity. Biochemistry (Mosc) 76(6):645-650

Zienkiewicz A, Zienkiewicz K, Rejón JD, Alché Jde D, Castro AJ, Rodríguez-García MI (2014) Olive seed protein bodies store degrading enzymes involved in mobilization of oil bodies. J Exp Bot 65(1):103-115 